\title{
Opportunistic Screening for Hypertension, Overweight and Obesity among Companions of Patients Attending the Family Medicine Clinic of a Nigerian Tertiary Hospital
}

\author{
Oyeyemi Olaniran $^{1 *}$, Olayinka O Ogunleye $e^{2,3}$ and Funke Ojomu ${ }^{1}$ \\ ${ }^{1}$ Department of Family Medicine, Lagos State University Teaching Hospital, Lagos, Nigeria \\ ${ }^{2}$ Department of Pharmacology, Therapeutics and Toxicology, Lagos State University College of Medicine, Lagos, Nigeria \\ ${ }^{3}$ Department of Medicine, Lagos State University Teaching Hospital, Lagos, Nigeria
}

*Corresponding author: Dr. Oyeyemi Olaniran, Department of Family Medicine, Lagos State University Teaching Hospital, Ikeja, Lagos, Nigeria, Tel: +234-803-431-5462

\begin{abstract}
Background: Current evidence reveals that the prevalence of hypertension and obesity is rising, and health care providers have the responsibility to treat a fast-growing population of individuals with these diseases. Health providers focus interventions on their patients, while ignoring the burden of non-communicable diseases in family members. Patients, particularly those with chronic diseases, often come accompanied to clinic visits by caregivers, family members or paid employees. This presents an often-ignored opportunity for screening these companions for common diseases like hypertension and obesity which when detected early can prevent severe morbidity and mortality. Screening family members for hypertension and obesity would lead to early case detection and management of these conditions. Early treatment of which will prevent complications and enable companions care better for patients. There is a dearth of literature on the prevalence of hypertension and obesity in companions of patients in this environment. This study aimed to determine the prevalence of hypertension and obesity among companions of patients seeking medical care at the Family Medicine Clinic of Lagos State University Teaching Hospital (LASUTH).

Methods: Four hundred and twenty-two companions of patients attending the Family Medicine Clinic, LASUTH were recruited and screened for hypertension and obesity. The socio-demographic characteristics, illness perception, attitudes and practice of companions, and their physical examination findings were obtained and summarized with appropriate statistics using SPSS version 20. All statistical tests were carried out at $95 \%$ level of significance.
\end{abstract}

\begin{abstract}
Results: A total of $24.4 \%$ of the patients attended the clinic with companions during the duration of the study. Companions of patients were mostly family members (95.8\%). The prevalence of hypertension, overweight and obesity in them was $50.47 \%, 31 \%$ and $61.8 \%$ respectively. Raised blood pressure was found to increase with age. Awareness of hypertension was low (26.8\%). Forty-two (42.4\%) percent of the companions had BP readings in the pre-hypertension range.
\end{abstract}

Conclusions: Hypertension and obesity were prevalent among companions of patients. Health promoting measures among caregivers should be integrated in the health care services provided for patients.

\section{Keywords}

Opportunistic screening, Companions, Hypertension, Obesity

\section{Background}

Hypertension is an important public health challenge in both developed and developing countries. It has been estimated that more than $50 \%$ of the hypertensive population globally are unaware of their condition [1]. This is consistent with the findings of a survey of the burden of hypertension in four sub-Saharan African countries including Nigeria where only $50 \%$ of the hypertensives were aware of their conditions [2].

Raised blood pressure, which is the leading glob-

Citation: Olaniran O, Ogunleye OO, Ojomu F (2020) Opportunistic Screening for Hypertension, Overweight and Obesity among Companions of Patients Attending the Family Medicine Clinic of a Nigerian Tertiary Hospital. J Hypertens Manag 6:045. doi.org/10.23937/2474-3690/1510045

Accepted: January 07, 2020: Published: January 09, 2020

Copyright: (c) 2020 Olaniran O, et al. This is an open-access article distributed under the terms of the Creative Commons Attribution License, which permits unrestricted use, distribution, and reproduction in any medium, provided the original author and source are credited. 
al risk factor for cardiovascular disease and chronic kidney disease is on the rise [3]. The number of people with raised blood pressure in the world increased from 594 million in 1975 to 1.13 billion in 2015 with the increase occurring mostly in low-income and middle-income countries [4]. This trend is projected to continue with a predicted $24 \%$ and $80 \%$ increases in the prevalence in developed and developing countries respectively, translating to 1.56 billion people globally by 2025 (333 million in developed countries and 639 million in economically developing ones like Africa and Latin America) [5,6]. Currently, the prevalence of hypertension in urban regions of Nigeria into which our study setting falls is estimated at 30.6\% [7].

High blood pressure is the leading risk factor for deaths due to cardiovascular disease, chronic kidney disease and diabetes in practically all the regions of the world accounting for more than $40 \%$ of the world-wide deaths from these diseases while high Body Mass Index (BMI) was found to be responsible for $15 \%$ of deaths worldwide [3]. Risk estimates from population studies indicate that at least two-thirds of the prevalence of hypertension can be directly attributed to obesity [8]. Obesity can increase the risk of hypertension to five folds as compared with those of normal weight, and up to two-thirds of hypertension cases can be attributed to excess weight with more than $85 \%$ of hypertension occurring in those with a body mass index greater than $25 \mathrm{~kg} / \mathrm{m}[2,8]$.

Screening in medicine is often used to identify a yet to be recognized disease in an apparently healthy, asymptomatic individual by means of tests, examination or other procedures that can be carried out easily and rapidly [9]. For diseases like hypertension and obesity, all it takes is a simple measurement that essentially determines the next steps towards diagnosis and treatment. The United States Preventive Task Force recommends screening for high blood pressure in adults aged 18 years and older for early detection of hypertension to reduce morbidity and mortality from cardiovascular diseases [10]. Opportunistic screening for high blood pressure has been shown to increase hypertension awareness and helps to leverage existing resources and infrastructure as well as facilitate transition to receiving subsequent treatment [11]. Despite its established usefulness in hypertension detection, there remains paucity of information in the literature regarding opportunistic screening for hypertension, obesity and other cardiovascular risk factors in Nigeria. This study was therefore carried out as an opportunistic screening of companions of patients attending the Family Medicine Clinic of a Nigerian Urban Teaching Hospital for hypertension, overweight and obesity.

\section{Methods}

This was a descriptive cross-sectional study that screened companions of patients attending the Fam- ily Medicine Clinic of Lagos State University Teaching Hospital, Ikeja, Lagos for hypertension, overweight and obesity carried out between July and August 2012. The hospital is a major referral center in Lagos metropolis with a bed capacity of 774 and is one of three tertiary centers serving an estimated catchment population of over 19 million people in Lagos State, Nigeria.

All companions of patients seeking medical care at the Family Medicine Clinic older than eighteen years who gave written informed consent except pregnant or patients with emergencies were recruited for the study. Interviewer administered questionnaires were completed by the investigator. Measurements of the blood pressure, weight and height of the consenting companions of patients attending the clinic were carried out.

Blood pressure was recorded using a mercury sphygmomanometer with proper size cuffs after at least 5 minutes of rest. The participants were seated on a chair with back support, feet on the floor, and arm supported at heart level. The manometer was at eye level, easy to read and deflated to zero before measurement. Two separate measurements in the left arm and a third reading in the right arm were taken. Systolic blood pressure was taken as the point at which the first of two or more sounds is heard (phase 1) and diastolic blood pressure was taken as the point before the disappearance of sounds (phase 5). Systolic and diastolic blood pressures were reported as the mean of 3 measurements. Blood pressure was classified according to the JNC 7 classification [12].

Body weight was measured without shoes, light clothing, emptied pockets using a physician's scale with a sensitivity of $0.5 \mathrm{~kg}$. Height was measured with subject standing against a wall-mounted stadiometer without shoes nor head gear.

Using the weight and height, the body mass index (BMI) was calculated using the formula weight/height $\left(\mathrm{kg} / \mathrm{m}^{2}\right)$. The BMI was classified according to the WHO classification [13].

Data was entered, cleansed and analyzed using Statistical Package for the Social Sciences (SPSS) version 20. Categorical variables were compared using Chi square tests. All statistical tests were carried out at $95 \%$ level of significance.

\section{Results}

A total of 5,428 patients were seen in the department of Family Medicine of the Lagos State University Teaching Hospital between July and August 2012 of which 1,322 (24.3\%) patients were accompanied. Four hundred and twenty-two companions that consented and met inclusion criteria were consecutively recruited for the study. 
Table 1: Socio-demographic characteristics of respondents.

\begin{tabular}{|c|c|}
\hline Characteristics & $\begin{array}{l}\text { Number (percentage of } \\
\text { respondents \%) }\end{array}$ \\
\hline \multicolumn{2}{|l|}{ Age (years) } \\
\hline$<25$ & $27(6.4)$ \\
\hline $25-34$ & $100(23.7)$ \\
\hline $35-44$ & $138(32.7)$ \\
\hline $45-54$ & $110(26.0)$ \\
\hline $55-64$ & $29(6.9)$ \\
\hline$\geq 65$ & $18(4.3)$ \\
\hline \multicolumn{2}{|l|}{ Sex } \\
\hline Male & $169(40)$ \\
\hline Female & $253(60)$ \\
\hline \multicolumn{2}{|l|}{ Religion } \\
\hline Christianity & $315(74.6)$ \\
\hline Islam & $107(25.4)$ \\
\hline \multicolumn{2}{|c|}{ Educational status } \\
\hline None & $24(5.7)$ \\
\hline Primary & $73(17.3)$ \\
\hline Secondary & $129(30.6)$ \\
\hline Post-secondary & $196(46.4)$ \\
\hline \multicolumn{2}{|l|}{ Tribe } \\
\hline Hausa & $13(3.1)$ \\
\hline Igbo & $86(20.4)$ \\
\hline Yoruba & $246(58.3)$ \\
\hline Others & $76(18.0)$ \\
\hline Non-Nigerian & $1(0.2)$ \\
\hline \multicolumn{2}{|l|}{ Marital status } \\
\hline Single & $97(23)$ \\
\hline Married & $294(69.6)$ \\
\hline Divorced & $5(1.2)$ \\
\hline Widowed & $26(6.2)$ \\
\hline \multicolumn{2}{|l|}{ Occupation } \\
\hline Civil servants & $77(18.2)$ \\
\hline Professional & $49(11.6)$ \\
\hline Business people & $63(14.9)$ \\
\hline Trader & $113(26.8)$ \\
\hline Artisan & $39(9.2)$ \\
\hline Student & $31(7.3)$ \\
\hline Unemployed & $21(5.0)$ \\
\hline Retired & $19(4.5)$ \\
\hline Others & $10(2.5)$ \\
\hline \multicolumn{2}{|l|}{ Income status } \\
\hline Low & $64(15.2)$ \\
\hline Medium & $147(34.8)$ \\
\hline High & $24(5.7)$ \\
\hline No response & $187(44.3)$ \\
\hline
\end{tabular}

The age range was $18-79$ years with a mean age of $40.9 \pm 11.0$ years. They were mostly females $(60 \%)$. About one third of the companions $(32.7 \%)$ were in
Figure 1: The relationship of companions to index patients.

\begin{tabular}{|l|l|}
\hline Relationship to Index Patient & $\begin{array}{l}\text { Number of } \\
\text { Respondents }\end{array}$ \\
\hline Spouse & $49(12 \%)$ \\
\hline Child & $190(45 \%)$ \\
\hline Sibling & $28(7 \%)$ \\
\hline Parent & $88(21 \%)$ \\
\hline In-law & $20(5 \%)$ \\
\hline Others & $47(11 \%)$ \\
\hline
\end{tabular}

the 35-44 years age group, while only few respondents $(4.3 \%)$ were aged 65 years and older. Nearly half $(46.4 \%)$ of the companions had post-secondary level of education while only $5.7 \%$ had no formal education. About a quarter (26.8\%) of the companions were petty traders, while nearly one fifth $(18.2 \%)$ were civil servants. Other socio-demographic characteristics are summarized in Table 1.

\section{Relationship of the Companions to the Index Patients}

One hundred and ninety (45\%) of the companions were adult children of the index patient (the patient the respondents accompanied to the clinic), while eighty-eight (20.9\%) were parents. Spouses accounted for only $11.6 \%$. Figure 1 shows the relationship of companions to the index patient. The group classified as others consist of neighbors, friends, aunts, uncles, nieces, nephews, grandchildren, cousins, colleagues, employers and employees. Colleagues, employers and employees accounted for $1.25 \%$, while neighbors, and friends were $2.4 \%$ of the respondents.

\section{Lifestyle and Medical History of Companions}

About a third $(30.1 \%)$ of the companions answered that they exercised regularly but only $30(7.3 \%)$ actually exercised three or more times a week. Eighty five (20.1\%) of the respondents admitted to taking alcohol while only two (0.5\%) smoked cigarettes.

One hundred and thirteen companions (26.8\%) had a previous high blood pressure reading of which seventy four (65.4\%) had used blood pressure lowering agents in the past while only forty nine $(43.4 \%)$ were currently on medication for hypertension. Nine $(18.4 \%)$ of the companions currently on medication for hypertension used other measures in addition to drugs to lower blood pressure. These included lifestyle modification like weight loss, low salt diet while $8.2 \%$ used herbal remedies.

\section{Pattern of Blood Pressure among Companions}

Two hundred and thirteen (50.47\%) companions had raised blood pressure (stage 1 and 2) while only $7.1 \%$ had normal blood pressure, the others $(42.4 \%)$ had pre-hypertension. Figure 2 shows the blood pressure pattern of respondents. 


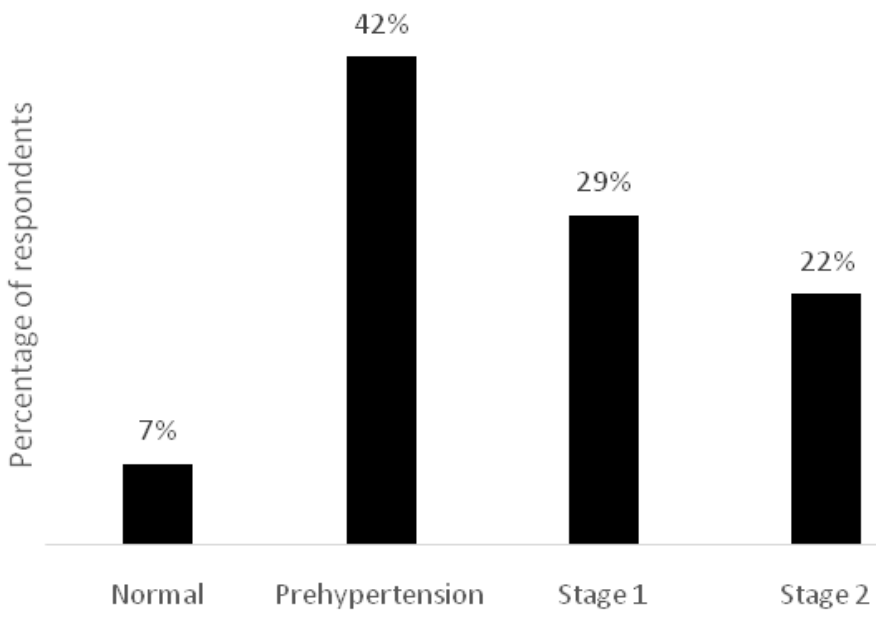

Pattern of blood pressure

Figure 2: Pattern of blood pressure among respondents.

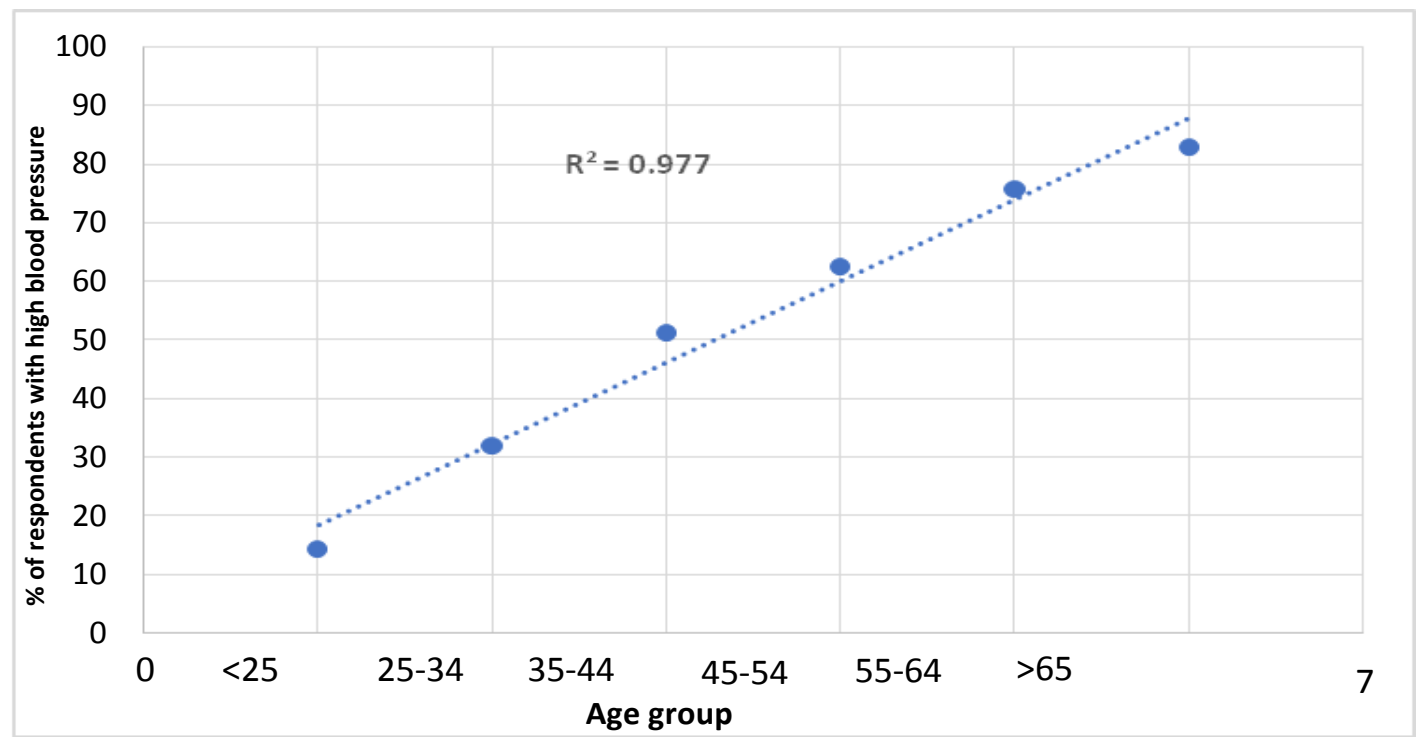

Figure 3: Prevalence of Hypetension among age groups of companions.

The proportion of raised blood pressure was noticed to increase across age groups; $14.4 \%$ in those less than 25 years of age, $32 \%$ in the $25-34$ years group, $51.4 \%$ in the $35-44$ years of age, $62.7 \%$ in the $45-54$ years group, and $83.3 \%$ in those older than 65 years. The mean systolic blood pressure was $137 \pm 23$ (SD) $\mathrm{mmHg}$ and mean diastolic blood pressure was $81 \pm 12$ (SD) $\mathrm{mmHg}$. Figure 3 shows a scatter plot of correlation between blood pressure and age.

\section{Pattern of Body Mass Index among Respon- dents}

Figure 4 shows the pattern of body mass index among respondents. More than half $(61.8 \%)$ of the respondents were overweight or obese, $31.0 \%$ and $25.4 \%$ respectively. $38.2 \%$ had normal body mass index, however only one hundred $(23.7 \%)$ of respondents considered themselves overweight or obese. The mean BMI was $27 \pm 13$ (SD) kg/m².

\section{Discussion}

In this study, 213 (50.47\%) companions had blood pressure in the hypertensive range. This finding is consistent with the prevalence of hypertension of $50.5 \%$ obtained in a previous Nigerian study carried out in a similar setting of a general outpatient clinic of a tertiary hospital in a semi-urban population [14].

The non-communicable disease study carried out in Nigeria in 1997 using a cut-off of 160/95 mmHg, which put the crude prevalence of hypertension as $11.2 \%$ can no longer be representative of the true picture of hypertension in the country [15]. Other more recent community based studies in Nigeria have recorded prevalence of $42.2 \%$ (Enugu, south eastern Nigeria) and 40\% (Katsina, North Eastern Nigeria), attesting to the fact that the prevalence of hypertension is rising in Nigeria $[16,17]$. This makes a case for using every opportunity to screen people for 


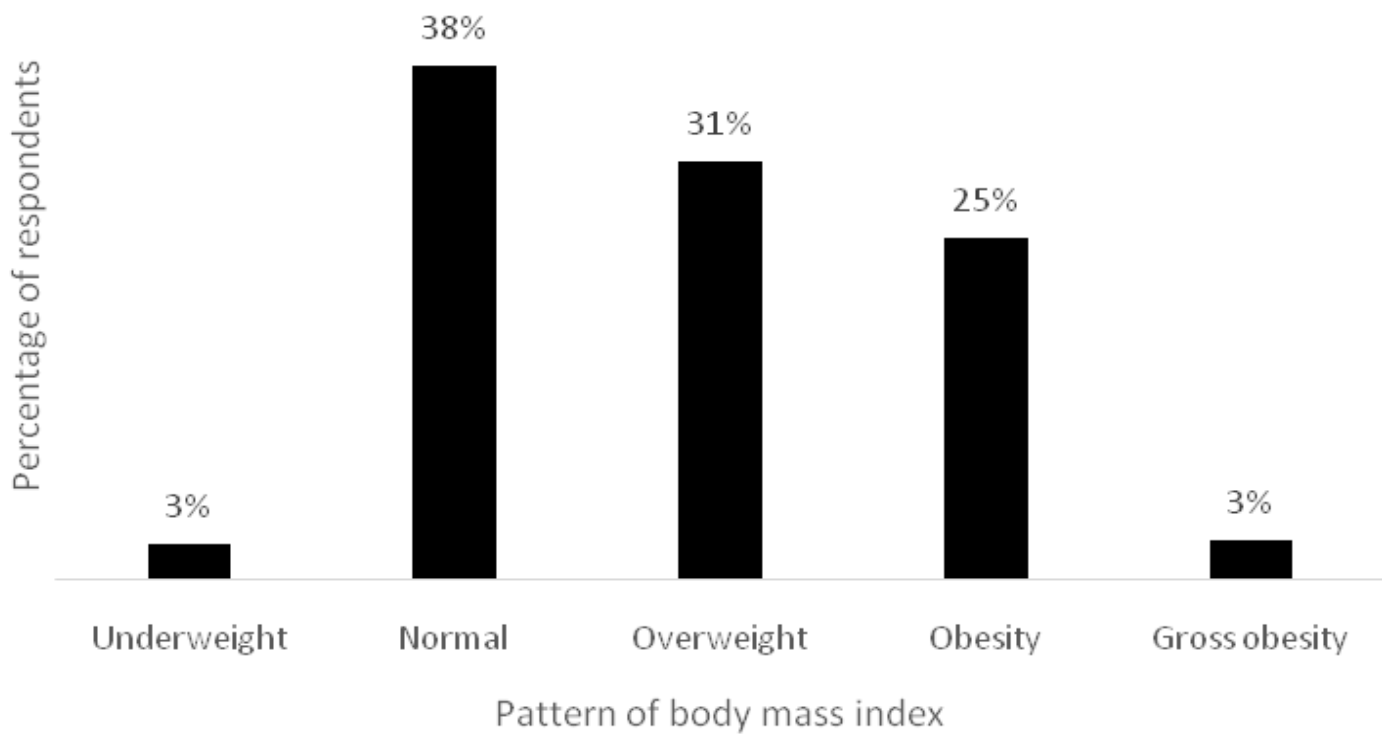

Figure 4: Pattern of body mass index of companions.

hypertension as this will lead to early treatment and subsequently reduce morbidity and mortality.

Raised blood pressure was found to increase with age. This is a well-documented fact and is consistent with recent community based studies carried out in Lagos and Ashanti, Ghana, West Africa $[7,18]$. The finding of $42.4 \%$ companions with prehypertension is comparable to the $48 \%$ observed in the community based study carried out in Katsina, Nigeria [17]. The low awareness $(26.8 \%)$ of hypertension seen in this study is also in keeping with a study done in Enugu, South-eastern Nigeria (29.4\%) [18]. Though most of the companions checked their blood pressure, they could not remember the reading and even when treatment was commenced, most defaulted. This may be due to poor follow up or erroneously ascribing a subsequent normal blood pressure reading to a cure.

More than half $(61.8 \%)$ of the companions were overweight or obese. A study of adult Nigerians in the northern part of the country found $73.3 \%$ of the population to be overweight or obese [19]. This high prevalence of obesity and overweight may be due to westernization of diets and increase in sedentary living especially in the urban region of the country. Less than a quarter $(23.7 \%)$ of the companions considered themselves overweight or obese. Again, this could be due to people not considering obesity a health problem but a way of life and evidence of good living. This level of awareness is however better than the previous record of $14.8 \%$ level of awareness of being overweight or obese in a study carried out in South- East Nigeria [20].

The proportion of accompanied clinic visits in this study is $24.4 \%$. Three hundred and fifty-three (83.6\%) companions had checked their blood pressure in the past and $72 \%$ did so in the last one year. This may have resulted from blood pressure screening routinely car- ried out in primary health centers when patients present with other complaints [21]. It may also have resulted from population screening programs carried out by religious organizations, pharmacies and the State government occasionally.

Surprisingly, fewer people (75.1\%) had ever checked their weight with only $52.4 \%$ doing so the previous year. One would have expected more people to check their weight because a scale is easier to use and not operator (medical personnel) dependent. This may have been because in this environment, being overweight is seen as a sign of affluence and is thought not to be associated with any morbidity.

Thirty percent $(30 \%)$ of the companions exercised regularly. This is low compared to the study in the North Eastern part of Nigeria which had $75 \%$ in the urban and $91.8 \%$ in the rural region who exercised regularly [17]. This may be explained by the fact that Lagos is a fast-paced megacity where there is little time or space for leisure and majority of the population work long hours to make ends meet.

\section{Conclusion}

The prevalence of raised BP and obesity in this study was high. The presence of companions during clinic visits presents an opportunity for health screening and serves as a means of reaching out to other caregivers and family members. Family and Primary care physicians should use this opportunity for screening companions of patients for hypertension, obesity and other diseases like diabetes mellitus.

\section{Study Limitations}

The study was carried out in an upbeat and busy urban area where people may not have the time to accompany their relatives. Perhaps a higher prevalence would be obtained in a less busy rural area. 
It was observed that other health care workers initially saw the screening of companions as prolonging each clinic consultation, but they were counseled and were themselves alarmed at the proportion of raised $B P$ in the first few companions screened. Hence, they later cooperated and were referring all the patients that came accompanied to the researcher even after the study was concluded. Blood pressure was taken on 3 consecutive times in a single visit as against the standard prescribed by the guideline. Our study did not provide biochemical parameters (blood glucose, serum lipids) due to logistics and funding, we acknowledge that these would have given more credence to our data.

\section{Funding}

This study was self-funded by the authors.

\section{Authors Contributions}

$\mathrm{OO}$ and $\mathrm{FO}$ conceived the study, OO, OOO and FO designed the study, $\mathrm{OO}$ and $\mathrm{FO}$ collected the data, $\mathrm{OO}$, $\mathrm{OOO}$ and FO analyzed the data, OO drafted the manuscript while $\mathrm{OOO}$ and FO contributed to the manuscript development and review. All authors read and approved the final manuscript.

\section{References}

1. Chockalingam A (2008) World hypertension day and Global awareness. Can J Cardiol 24: 441-444.

2. Guwatudde D, Nankya-Mutyoba J, Kalyesubula R, Laurence C, Adebamowo C, et al. (2015) The burden of hypertension in sub-Saharan Africa: A four-country cross sectional study. BMC Public Health.

3. Global Burden of Metabolic Risk Factors for Chronic Diseases Collaboration (2014) Cardiovascular disease, chronic kidney disease, and mortality burden of cardiometabolic risk factors from 1980 to 2010: A comparative risk assessment. Lancet Diabetes Endocrinol 2: 634-647.

4. NCD Risk Factor Collaboration (NCD-RisC) (2016) Worldwide trends in blood pressure from 1975-2015: A pooled analysis of 1479 population-based measurement studies with 19.1 million participants. 389: 37-55

5. Kearney PM, Whelton M, Reynolds K, Whelton PK, He J (2005) Global burden of hypertension: Analysis of worldwide data. Lancet 365: 217-223.

6. Collins AJ (2012) Prevalence of diseases.

7. Adeloye D, Basquill C, Aderemi AV, Thompson JY, Obi FA (2015) An estimate of the prevalence of hypertension in $\mathrm{Ni}$ geria: A systematic review and meta-analysis. J Hypertens 33: $230-242$.
8. Markiewicz K (2006) Obesity and hypertension, the issue is more complex than we thought. NephDiaTra 21: 264-267.

9. World Health Organization. Cancer Screening.

10. Piper MA, Evans CV, Burda BA, Margolis KL, O'Conner E, et al. (2014) Screening for high blood pressure in adults. A systemic evidence review for the United States Preventive Services Task Force. Agency for Healthcare Research and Quality.

11. Maurer J, Ramos A (2005) One-year routine opportunistic screening for hypertension in formal medical settings and potential improvements in hypertension awareness among older persons in developing countries: Evidence from the study in Global Ageing and Adult health (SAGE). Am J Epidemiol 181: 180-184.

12. JAMA (2003) The seventh report of the Joint National Committee on Prevention, Detection, Evaluation and treatment of High Blood Pressure: The JNC 7 Report. JAMA 289: 2560-2572.

13. (2017) World Health Organization. Obesity.

14. Omole IO, Olaolorun AD, Odeigah LO, Adesina SA (2011) The prevalence of abdominal obesity and hypertension amongst adults in Ogbomoso, Nigeria. Afr J Pri Car Fam Med 3: 1-5.

15. Akinkugbe OO (1997) Final report of a national survey. Lagos, Nigeria: Ministry of health and social services. Non-communicable diseases in Nigeria 5-41.

16. Ulasi I, ljoma CK, Onodugo OD (2010) A Community based study of hypertension and metabolic syndrome in semi-urban and rural communities in nigeria. BioMed Central. Health Services Research 10: 71.

17. Nwankwo EA, Ene AC, Biyaya B (2008) Some cardiovascular risk factors in volunteers for health checks: A study of rural and urban residents in the North east of Nigeria. Inter J Cardiov Reas 5.

18. Ulasil, ljoma C, Onwulere B, Okafor C (2011) High prevalence and low awareness of hypertension in a market population in Enugu, Nigeria. Int J Hypertens.

19. Wahab KW, Sani MU, Yusuf BO, Gbadamosi M, Gbadamosi A, et al. (2011) Prevalence and determinants of obesity-a cross sectional study of an adult Nigerian population. Int Arch Med 4: 10

20. Iloh GU, Amadi AN, Nwankwo BO (2010) Obesity in adult Nigerians: A study of its prevalence and common primary co-morbidities in a semi-urban Mission General Hospital in South Eastern Nigeria. Niger J Med 19: 459-466.

21. Canadian task Force on Preventive health care and the Canadian hypertension education program. Recommendations on screening for high blood pressure in Canadian adults. 